\title{
XCVIII. The scattering of the $\beta$ rays of radium
}

\section{J.P.V. Madsen D.Sc. B.E.}

To cite this article: J.P.V. Madsen D.Sc. B.E. (1909) XCVIII. The scattering of the $\beta$ rays of radium , Philosophical Magazine Series 6, 18:108, 909-915, DOI: 10.1080/14786441208636768

To link to this article: http://dx.doi.org/10.1080/14786441208636768

册 Published online: 21 Apr 2009.

Submit your article to this journal $₫$

Џ Article views: 2

Q View related articles $₫$

4 Citing articles: 2 View citing articles 진 
XCVIII. The Scattering of the $\beta$ Rays of Radium. By J. P. V. Madsen, D.Sc. (Adel.), B.E. (Syd.), Lecturer in Electrical Engineering, Univerity of Adelaide*.

\section{[Plate XXX.]}

\section{$\S$ I. Introductory.}

I $N$ a paper by the author upon the secondary $\gamma$ rays $\dagger$ it 1 was shown that in passing through matter the $\gamma$ rays were scattered and softened. The scattered radiation showed a distinct lack of symmetry about a plane perpendicular to the direction of the original stream, more scattered radiation moving on in the direction of the original stream than was turned back. The distribution of the scattered radiation was found to depend upon the quality of the incident radiation and also upon the nature of the medium in which the scattering occurred.

As the results arrived at in that investigation were used as an argument in support of the material theory of $\gamma$ rays proposed by Bragg, and as Crowther $\ddagger$ has recently shown that the $\beta$ rays are subject to scattering by even very thin layers of material, it became of special interest to see whether any parallel could be drawn between the effects of scattering in the case of the material $\beta$ particles and the $\gamma$ rays.

It will be seen from the present paper that the parallel is very close in many respects, the differences being such as might reasonably be expected on the theory that the $\gamma$ ray is a neutral pair.

At the same time it is hoped that some of the results to be described may help to clear up some of the difficulties which have arisen in the study of the absorption of $\beta$ rays.

\section{§ II. Apparatus.}

The apparatus used in these experiments is shown in fig. 1. The radium contained in a small conical hole cut in a piece of $\mathrm{Al}$ was covered by a sheet of $\mathrm{Cu}$ foil $\cdot 002 \mathrm{~cm}$. thick. The $\beta$ rays passed up through a conical hole cut in a block of

* Communicated by the Author. From 'Transactions of the Royal Society of South Australia,' vol. xxxiii. 1909. Preliminary Account read hefore the Austrulasian Association for the Advancement of Science, Brisbane, January 13, 1909.

t Trans. Roy. Soc. S.A. vol. xxxii. (1908).

\pm Proc. Roy. Soc., A, vol. Ixxx. (1908). 
wood, portions of the block being removed as shown to allow of the introduction of the screens in different positions as at A, B, C. The ionization-chamber was hemispherical and made of wood, with the inner surface covered with very thin

Fig. 1.

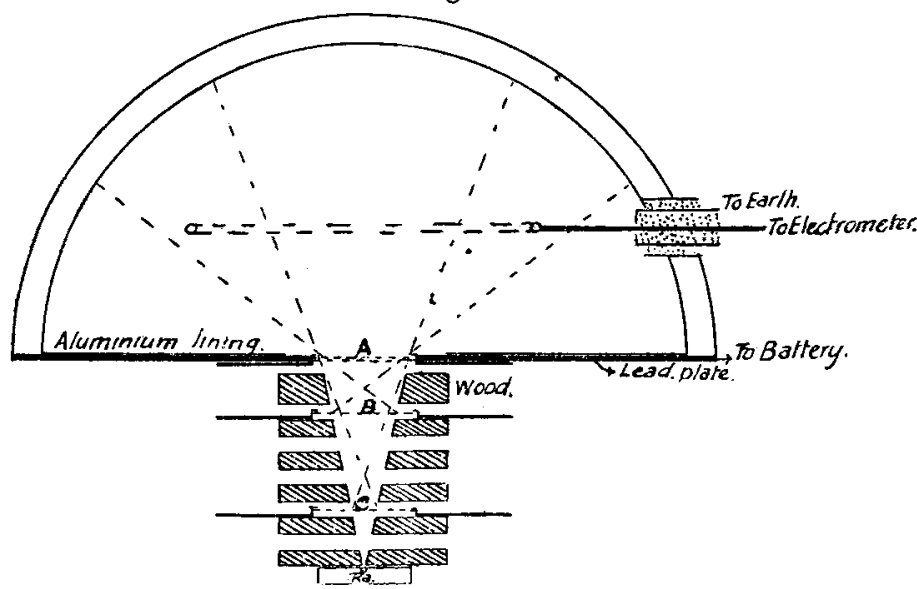

Al foil. The electrode connecting to the electrometer was in the form of a circular ring of wire, suitably protected by the usual methods. The hemispherical chamber rested upon a circular plate of $\mathrm{Pb}$, above which was laid a sheet of $\mathrm{Al}$. $\mathrm{A}$ circular hole cut centrally in the $\mathrm{Pb}$ and $\mathrm{Al}$ plates enabled the screen to be placed in the position $A$. In this position practically all the emergent scattered radiation was able to produce its effect to the same extent as the rays in the main stream, all rays having the same length of path in which to produce ionization, and the complications of secondary effects being reduced by having the walls of the chamber wood.

If we may for the present neglect any alteration in speed of the scattered radiation and consider the original stream of rays more or less homogeneous, the current may be taken approximately as a measure of the number of $\beta$ particles which enter the chamber, no matter what their direction, proper correction being made for the effect produced by $\gamma$ rays.

By subtracting the readings taken with a screen at $\mathrm{A}$ and at $\mathrm{C}$ a measure is obtained of the amount of radiation which has been turned out of its original path or scattered by that screen. Another reading with the screen at $B$ enabled the distribution of the emergent scattered radiation to be followed out. 
To obtain a measure of the returned, or incident, scattered radiation the apparatus shown in fig. 2 was used.

Fig. 2.

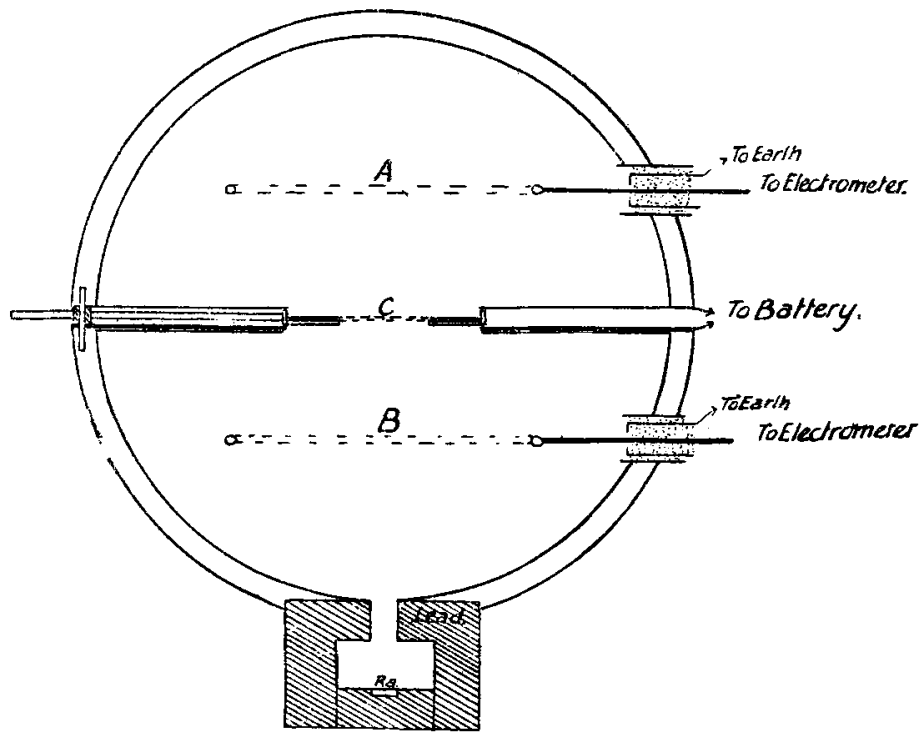

The top chamber, $A$, was the one already described, and a similar hemispherical chamber, B, was placed as shown with the Ra outside, contained in a $\mathrm{Pb}$ block provided with an opening through which the $\beta$ rays could pass, impinging on screens placed in the position $\mathrm{C}$. A stronger sample of $\mathrm{Ra}$, kindly lent by Dr. Hermann Laurence, was used in these experiments, but care was taken to cover it with $\mathrm{Cu}$ foil, as in the first set of experiments. Either of the electrodes A or B could be connected to the electrometer, and as the chambers were made as nearly as possible alike no appreciable change in capacity was introduced, using either chamber separately. It was necessary to use a balance chamber, as the initial effect was so large compared with that which. was to be measured. By placing a thin $\mathrm{Al}$ foil at $\mathrm{C}$ and then a thick $\mathrm{Pb}$ plate, a measure was obtained of the incident and of the maximum return radiation for that substance, from the effects measured separately in the chambers A and B. This enabled the readings for the incident scattered radiation to be reduced to their correct values relatively to those of the emergent rays, using the maximum return radiation from $\mathrm{Pb}$ as a standard of reference. 


\section{$\S$ III. Results of Experiments.}

Fig. 3 (Pl. XXX.) shows the results of experiments performed with the apparatus of fig. 1, using Al screens.

Curves $D$ and $E$ give the currents for different thicknesses of screen, with the screens in the positions $A$ and $C$ respectively. The abscissæ represent grammes per square cm. from which the thickness of screen may be immediately deduced, knowing its density.

Curve $\mathrm{C}$ is obtained by subtracting the values of $\mathrm{D}$ and $\mathrm{E}$ corresponding to any screen, and is a measure of the total amount of emergent scattered radiation.

It will be seen from fig. 1 that the whole of the scattered radiation is not quite included, as the effects are somewhat interfered with by geometrical conditions. When, for example, the screen was brought nearer the $\mathrm{Ra}$ than $\mathrm{C}$ a slight rise was observed in the reading. The intensity of the radiation falling on the screen was slightly increased owing to some of the more oblique rays from the $\mathrm{Ra}$ being now able to fall upon the screen.

Curves $A$ and $B$ represent the results of subtracting readings with the screen at $B$ and $C$ and $A$ and $B$ respectively (fig. 1), and are measures of the amount of radiation slightly deflected, and of that which has suffered much larger deflexion.

Curve $F$ represents the returned radiation from aluminium screens of different thicknesses. Similar curves to the above are shown in fig. 4 for Au screens.

\section{$\S$ IV. Discussion of Results.}

In fig. 3, from curve $\mathrm{C}$, it is seen that the total emergent scattered radiation increases rapidly to a maximum, and then steadily decreases as the thickness of screen is increased. The maximum occurs at about $\cdot 013 \mathrm{~cm}$.

Comparing the curves $\mathrm{C}$ and $\mathrm{F}$, it is seen that for thin screens the emergent is much greater than the incident scattered radiation The greatest value of the ratio is about $9: 1$.

Comparing the similar curves for Au, fig. 4, it is again seen that a considerable lack of symmetry exists between emergence and incidence radiation, though not so marked. In this case the greatest value of the ratio is about $4.5: 1$. The maximum for the emergence radiation is reached at about $\cdot 0008 \mathrm{~cm}$.

The effects of scattering in the case of $\beta$ rays are thus very similar to those observed for $\gamma$ rays, a material of high 
atomic weight being able to turn back in the process of scattoring more of the original radiation than a material of smaller atomic weight.

Comparing curves $\mathrm{A}$ and $\mathrm{B}$, it is observed that $\mathrm{A}$ reaches a maximum sooner than $B$. A more careful examination of $A$ and $B$ for smaller thicknesses of screen has shown that the ratio of $A$ to $B$ is practically constant until about onethird of the maximum reading is reached, after which the ratio gradually decreases. It would appear that while the ratio remains constant we are concerned with only a single collision of any $\beta$ particle, that as the screen is further thickened it becomes possible for a $\beta$ particle to suffer more than one collision before emerging, thus making the emergent beam appear to gradually swing round from its original direction, a greater thickness of screen being required to produce the maximum intensity for very oblique rays than for those corresponding more nearly with the direction of the original stream.

A fuller consideration of the effects of scattering and absorption for very thin films will be reserved for a future paper.

A theory of scattering sinilar to that proposed by Sir J. J. Thomson in 'Conduction of Electricity through Gases' seems capable of explaining the observed results. The nearness of approach of a $\beta$ ray to a constituent of an atom will determine the amount and nature of the deflexion experienced, the speed of the $\beta$ ray and the constitution of any particular atom being also necessary factors.

Until a $\beta$ ray is subject to more than one collision the distribution is approximately constant for a given material, the intensity of the radiation deflected by an angle $\theta$ from the original direction being a function of that angle for any one material and with rays of a given quality.

We are to consider this function of $\theta$ as being different for the different atoms.

The lack of symmetry in the distribution of scattered $\mathrm{X}$-rays has been shown by Bragg*, and assuming, as seems reasonable on many grounds, that $X$ - and $\gamma$-rays are of the same nature, it appears from that investigation that the softer radiation shows less want of symmetry when falling on a given material than does the harder.

Now although the lack of symmetry shown by the scattered $\beta$ rays is much greater than that found for $\gamma$ - and $X$-rays, even though the former are less penetrating, the general nature of the effect has been shown to be much the same in

* Trans. Roy. Soc. S. A. vol. xxxii. (1908). 
the case of all three, and the difference in magnitude may possibly be explained by the difference in distribution of the fields of the rays concerned.

Curves similar to C, figs. 3 and 4, have been obtained for $\mathrm{Ag}$ and paper; they show the same general characteristics. It is remarkable, however, that the maximum value of the curve $\mathrm{C}$ is very nearly the same for all the substances tested.

In a recent paper by McClelland ${ }^{*}$ an account is given of the distribution of the returned $\beta$ radiation from plates of different substances when the incident beam of radiation is inclined to the plate. The results seem capable of explanation, in view of the effects which have just been described, upon a theory of scattering without the need of introducing the idea of a true secondary radiation proceeding from the atoms affected by the incident $\beta$ rays.

The general effect observed by McClelland is that the distribution of the returned radiation is more uniform for $\mathrm{Pb}$ than for $\mathrm{Al}$. This is to be expected in view of the nature of distribution of the scattered rays from thin films of such substances as $\mathrm{Au}$ and $\mathrm{Al}$, which has been described in the present paper.

From the results shown in figs. 3 and 4 it is at once seen that the effects of scattering may considerably modify the results obtained in the usual form of absorption experiment with $\beta$ rays. The shape of the ionization-chamber and the positions of the screen and active material relatively to the chamber and to each other may produce considerable modifications in the results.

Again, in studying the absorption of $\beta$ rays it would seem necessary to deal with very thin screens as is necessary in observing the effects of scattering; for thicker screens the results are likely to become considerably complicated.

It would seem almost better to replace the name of "absorption coefficient," as it is usually employed, by that of " transmission coefficient," reserving the former as a measure of effects which, as has been explained, can probably be obtained only from a study of very thin screens.

If the interpretation of the foregoing experiments be correct it seems that the $\beta$ particle in traversing a thick screen may suffer many collisions and deflexions.

Now it has been shown by Allen (Phys. Review, Aug. 1906 ) that the secondary or reflected $\beta$ radiation consists of electrons moving on the whole with a somewhat slower speed than the original radiation.

As the experiments described in the present paper indicate that in some cases these reflected electrons have suffered

* Proc. Roy. Soc., Series A, vol. lxxx. 
many collisions before emerging, it would appear that the loss of energy due to a single collision is as a rule not very great, even though the effect of the collision may have produced a considerable change in the direction of motion of the electron. It is not surprising, then, that some of the returned rays have been found to have practically the same speed as some of the original rays; they would appear to be electrons which have suffered only one collision of sufficient violence to cause them to reverse their original direction of motion, or several minor collisions leading to the same result.

From the curves shown in figs. 3 and 4 (Pl. XXX.) it is seen that for small thicknesses of screen, before much actual absorption has occurred, the number of $\beta$ rays turned back may be large, so that many of the original rays would appear to lose their energy gradually, rather than by a very sudden stoppage and complete absorption. Since the cathode rays behave in many respects like the $\beta$ rays, it seems difficult to understand how the whole of the energy of the X-rays can be derived from the stoppaye of the cathode particles, for, as pointed out by Professor Bragg *, the stoppage must be very sudden for this to be the case.

\section{Summary.}

Experiments with the $\beta$ rays of radium support the results previously ohtained by Crowther, using uranium, upon the scattering of the rays by thin films of materials.

The distribution of the scattered $\beta$ rays is unsymmetrical, about a plane of right angles to the direction of the original stream.

A close parallel thus exists between the scattering of $\beta$ rays and that of $\gamma$ and $X$ rays.

The shape of the so-called absorption curve may be modified by the shape of the ionization-chamber and the position of the screen and active material relatively to the chamber and to each other.

Absorption of a beam of $\beta$ rays, combined with the effects of scattering and softening, seem sufficient to account for observed effects without the introduction of the idea of a true secondary radiation proceeding from the atoms affected by the primary stream of rays.

An electron appears to be able to suffer collisions, producing considerable change in its direction of motion, without any great loss of energy.

In conclusion, I wish to express rny best thanks to Professor Bragg for the suggestions he has kindly given me from time to time during this investigation.

University of Adelaide, Jan. 5, 1909.

* Trans. Roy. Soc. S. A. rol. xxxi. (1907), 
MADSEN.

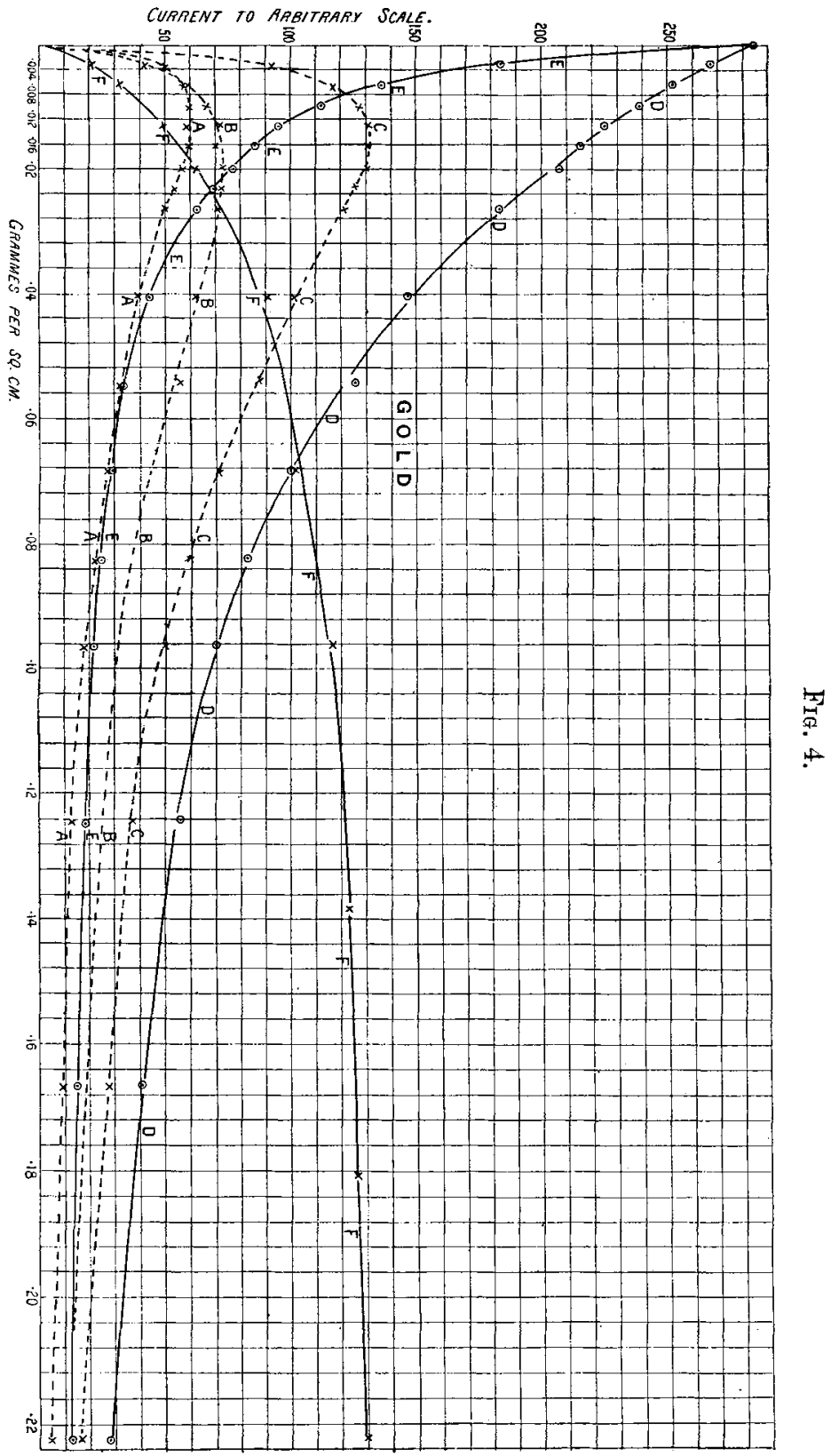


Phil. Mag. Ser. 6. Vol. 18, Pl. XXX.

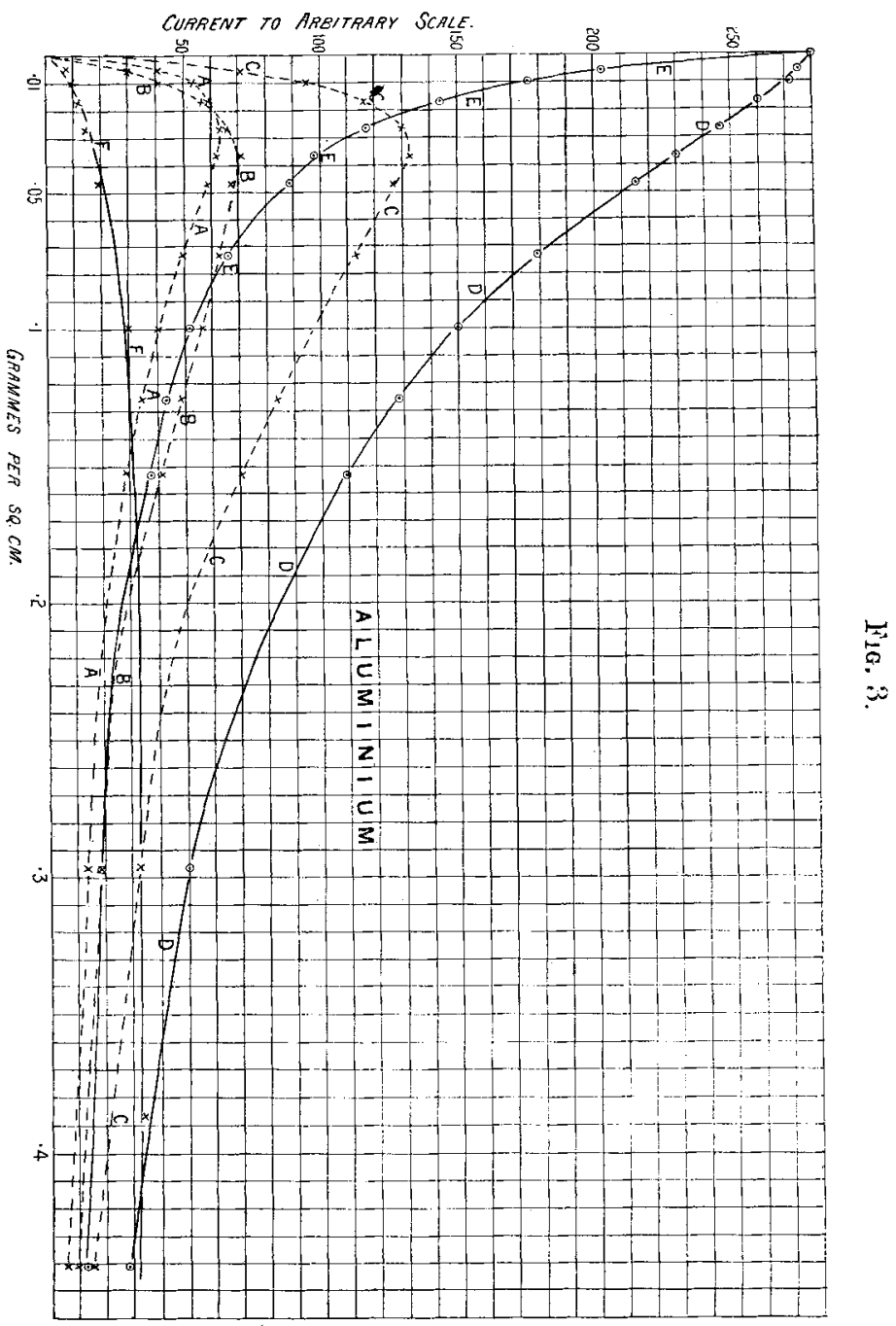

